\title{
RADIOGRAFÍAS DEL COSTARRICENSE: ENTRE CARMEN NARANJO Y FERNANDO CONTRERAS
}

\author{
Mayela Vallejos Ramírez
}

\begin{abstract}
RESUMEN
Este ensayo explora algunos aspectos de la identidad del costarricense a través del estudio de dos textos: 5 Temas en busca de un pensador de Carmen Naranjo Coto y Urbanoscopio de Fernando Contreras Castro. En este trabajo, se analizan las cinco expresiones (Ahí vamos, Qué le vamos a hacer, A mí que me importa, De por sí e Idiay) que Naranjo trabaja en su ensayo. Después examinaré cómo Contreras refleja estas expresiones en el quehacer diario del costarricense en algunas de sus viñetas. Esto nos permite examinar desde adentro la visión que tiene el costarricense del mundo y de sí mismo en relación con los aconteceres políticos, sociales y personales.

Palabras clave: idiosincrasia, individualismo, viñetas, indiferencia, costarricenses.
\end{abstract}

\begin{abstract}
This essay explores some aspects of the Costa Rican identity through the analysis of two books:5 Temas en busca de un pensador, written by Carmen Naranjo Coto and Urbanoscopio by Fernando Contreras Castro. In this work, I will analyze the five expressions of speech commonly used by Costa Ricans, (Ahí vamos, Qué le vamos a hacer, A mí que me importa, De por sí e Idiay) that Naranjo developed in her essay. I will then examine how Contreras reflects these expressions as part of the daily life of Costa Ricans in his short stories. This allows us to closely examine the concept that Costa Ricans have about themselves and the world in relation to political, social and personal issues.
\end{abstract}

Key words: Idiosyncrasy, individualism, vignettes, indifference, Costa Ricans.

En memoria a Carmen Naranjo Coto, maestra y amiga

\section{Introducción}

La consolidación de la identidad nacional costarricense a finales del siglo XIX y principios del XX fue marcada por una oligarquía cafetalera que tenía como objetivo sentar las bases de una sociedad liberal e independiente en el aspecto religioso, político y económico. A la

Dra. Mayela Vallejos Ramírez. Profesora catedrática. Department of Languages, Literature, and Mass Communications, Colorado Mesa University.

Correo: mvallejo@coloradomesa.edu

Recepción: 01- 02- 2012

Aceptación: 07- 02- 2012 
vez, los oligarcas de este periodo a través de la literatura y el arte en general crean una imagen nacionalista e idealizada del costarricense, la cual se ha mantenido hasta nuestros días. El problema de esta identidad colectiva nacional es el espejismo que se crea en torno a la realidad del costarricense que va por el mundo pensando que de verdad "somos la suiza centroamericana" y que no tenemos nada que envidiarle a los goces de Europa como enfatizan algunas estrofas de la "Patriótica costarricense" (1856) de la autoría de Roberto Gutiérrez y Carlos López:

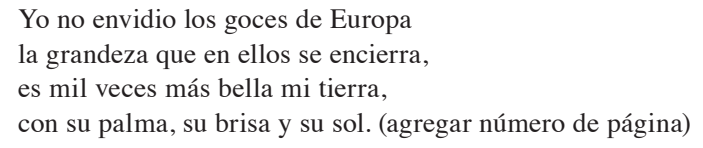

El problema no radica en el orgullo nacional que se debe sentir por la tierra que lo vio a uno nacer, pero en la miopía que esta genera si no se canaliza desde una perspectiva más crítica y objetiva. El libro, La formación de la Narrativa Nacional Costarricense (1890- 1910): Enfoque Histórico Social de Álvaro Quesada Soto (1986), plantea claramente algunos de estos aspectos que nos ayudan a vislumbrar las razones de la identidad nacional costarricense actual. Quesada Soto argumenta que a diferencia de otros países latinoamericanos en Costa Rica no se produjo una ruptura irreconciliable entre los oligarcas y el pueblo. Quesada Soto considera que:

\footnotetext{
Es dudoso, de acuerdo con estudios más recientes, que de veras existiera en Costa Rica colonial el "tono democrático e igualitario" que pretende Facio; pero su descripción de la hacienda como núcleo económico-social, y de las relaciones patriarcales, con su énfasis en los lazos personales y familiares entre sus componentes, es, creemos, fundamental para comprender la concepción del mundo y de la realidad del costarricense hasta bien entrado el siglo veinte. (Quesada 1986: 21)
}

Las relaciones patriarcales producidas en esta pequeña nación toman un camino muy sui generis porque los grandes cafetaleros se aseguran de mantener un pacto con el pequeño propietario y sus trabajadores, el cual crea una atmósfera para nada antagónica desarrollando más bien un sentimiento igualitario aunque la realidad sea muy diferente. Lo que ha venido a crear un sistema paternalista que está intrínsecamente relacionado con las relaciones familiares que abarcan la relación de trabajo. Esto crea una idiosincrasia muy particular, típica del costarricense como bien los señala Quesada Soto al citar un texto del escritor inglés Anthony Trollope quien hiciera un estudio del costarricense en su visita al país:

\footnotetext{
Son una raza lerda, resignada, tranquila, ordenada y amiga del dinero, pero en ningún caso de arriesgarlo... Se muestran ansiosos de hacer pequeñas economías y políticamente satisfechos si se les garantiza estas economías. Aún las clases altas o las que nosotros llamaríamos clase comerciantes, parecen poco deseosas de adquirir educación ya sea religiosa o profana. No tienen entusiasmo, ni ardientes deseos, ni aspiraciones. ... Pero llegado el caso de tratar con ellos, la cosa cambia. Su conciencia se hace elástica; y como en un trato libre de hombre a hombre, harán cuanto puedan por engañarnos. (Quesada 1986: 32)
}

La idiosincrasia de un pueblo entonces va a determinar su carácter particular. En el caso del costarricense nos encontramos frente a un individuo cuyos rasgos más relevantes se encuentran: la tolerancia, el choteo, el conformismo, la desconfianza, la pasividad y la indiferencia "frente a los problemas e intereses públicos y de la Comunidad" (1995: 56) como señala Jaime González Dobles en su libro La Patria del Tico. Compartimos con González Dobles, el hecho que estas características que han sido señaladas por muchos estudiosos como Eugenio Rodríguez, Luis Barahona, Gaetano Cersósimo y Enrique Macaya no "constituyen características reales y precisas de la conducta específicas de los ciudadanos: tan solo son elementos conceptuales que permiten detectar tendencias dominantes o énfasis predominantes" (González 1995: 57). 
Estos aspectos del ser costarricense se han tratado en muchos de los cuadros de costumbres de principios del siglo XX. En los cuales, se ha ensalzado o resaltado algunas de esas características que distinguen con su sello particular al tico. Por otra parte, escritores como Carmen Naranjo Coto (1928-2012) han sido muy críticos de algunas de estas concepciones que han venido estigmatizando al costarricense, ya que en vez de ayudarlo a desarrollarse como un ser pleno, lo minimiza y lo hace tomar una actitud derrotista, conformista e indiferente ante lo que acontece al país y sus conciudadanos. En su libro, 5 temas en busca de un pensador Naranjo (1989) por medio de un examen crítico de la sociedad plantea algunas frases preferidas de los ticos, las cuales reflejan aspectos importantes de la idiosincrasia nacional. Luz Ivette Martínez en su estudio sobre Naranjo Coto estima que "la ensayista ve como un imperativo reflexionar en las frases repetidas porque es imposible seguir viviendo en la inercia de hablar por medio de ruidos y negar las actitudes pensantes que existen detrás de las voces" (Martínez 1987: 151).

Por otro lado, nos encontramos a Fernando Contreras Castro, perteneciente a la nueva generación de escritores costarricenses denominada la "generación del desencanto" quien con gran sagacidad nos presenta otra visión del sentir y del actuar del costarricense por medio de pequeñas viñetas en su cuentario Urbanoscopio (2000). El trabajo de Contreras representa muy bien la literatura urbana que ha tenido una gran importancia en Latinoamérica en las últimas décadas y va "más allá de constituirse en un asunto, se asume como estilo y forma de ver el mundo y enfrentarlo" (Carrillo 2008: 65). En el ámbito citadino, se desarrollan estas historias, las cuales ponen en manifiesto los diferentes sucesos que le acontecen a diferentes personas pertenecientes a diversos estratos de la sociedad. Característico de este estilo literario, "la ciudad, su ambiente y los elementos que la constituyen, está impregnado de una atmósfera destructiva que proviene de ese nuevo rostro adquirido a través de la presencia de lo moderno" (Carrillo 2008: 68). Como el título del cuentario lo manifiesta, el narrador, con su ojo crítico está enfocándose en acontecimientos independientes que suceden en la sociedad urbana y cómo reaccionan los individuos a quienes les acontecen los eventos. Cada cuadro, por lo tanto, nos deja ver una muestra de las diferentes reacciones de ciertos individuos que viven en sus pequeños mundos sin importarles mucho su entorno político y social. Las viñetas presentadas por Contreras son fiel reflejo de lo que Carmen Naranjo ya había observado previas décadas atrás, una sociedad que se desmorona por la inercia y por la apatía ante los problemas reales porque es más fácil pretender que nada está pasando que afrontarlos.

Para efectos de este trabajo, quiero empezar por analizar las cinco expresiones trabajadas por Naranjo en su colección ensayística para luego compararlas con algunas de las viñetas de Fernando Contreras que muestran desde otra perspectiva la indiferencia e individualismo que ha caracterizado al tico.

\section{Cinco temas en busca de un pensador}

En su libro, Naranjo reflexiona sobre cinco expresiones de uso común del costaricense: Ahí vamos, Qué le vamos a hacer, A mí que me importa, De por sí e Idiay. Estas cinco expresiones muestran muchos aspectos del ser humano. Al analizarlas, Naranjo está tocando una serie de nervios sensibles de la humanidad como son la soledad, el miedo, los complejos y las inseguridades. Lo interesante de este texto es que a pesar de que Naranjo está describiendo aspectos específicos del ser costarricense, estas también podrían verse desde un punto de vista universal. Pues las actitudes que Naranjo plantea no son exclusivas de los costarricenses, aun 
más las frases analizadas en su ensayo son usadas por otros hispanohablantes. Sin embargo, estas cinco expresiones están intrínsecamente arraigadas en el ser costarricense y son fiel reflejo de la idiosincrasia de este pueblo. Coincidimos con Luz Ivette Martínez cuando dice que estructuralmente "cada apartado se constituye de tres partes: una reflexión general en torno a la frase, una aplicación específica al contexto costarricense y una exhortación final para que el hombre asuma actitudes positivas" (1987: 151).

Empezaré por la frase Ahí vamos. Con esta frase, Naranjo nos deja ver la situación que estamos viviendo. Los seres humanos disfrazamos nuestras vidas para sobrellevarlas. No nos enfrentamos a lo cotidiano solos. Necesitamos de la colectividad para poder dejar ver nuestra propia realidad:

\footnotetext{
Ahí vamos. Vamos porque no se anda solo y el hombre más abandonado responde vamos, porque incluye su soledad como compañía o porque esa soledad no existe y cada uno vive y se desdobla en el usted y el yo, un poco similar al lenguaje de los locos... En el ahí vamos nos hemos librado del terreno de la unidad aislante. En el nosotros damos cabida a la familia, al amigo, al jefe o personalizamos la soledad y marchamos con ella. (1989: 18)
}

Al mismo tiempo el Ahí vamos encierra una discontinuidad del ser. Realmente, no lleva una dirección clara de lo que está haciendo. Es más bien un lugar disperso. No está en ninguna parte, solo viene a reforzar la idea de lo absurdo de la vida del hombre moderno que vive en ese infinito laberinto. La ciudad lo ha atrapado y lo destruye ante la indiferencia del mundo.

En el costarricense, esta expresión no está relacionada con la colectividad sino más bien con la individualidad que ha sido una de las características sobresalientes del tico: "En nuestro medio el ahí vamos tiene un espíritu sumamente individual. Pues el sujeto no se hace colectivo de la humanidad" (1989: 25). El individualismo ha llevado al costarricense a limitar su visión del mundo. Los sucesos son meros acontecimientos que ni siquiera marcan una huella en la conciencia social. Esto se debe a que la relación del ciudadano con su mundo exterior está basada en sus propios intereses. En referencia al individualismo, González Dobles señala que "Luis Barahona considera el individualismo como central en la explicación de la conducta moral, económica, social y política del costarricense" (González 1995: 65). Por lo tanto, nos encontramos ante un individuo que "se concreta en un débil sentimiento solidario con lo ajeno y en la indiferencia con el bienestar del prójimo: insensible ante el desorden y extravío reinantes en la sociedad en la que vive" (González 1995: 65).

Asimismo, la expresión Que le vamos a hacer encierra una visión bastante negativa de la vida. Con esta frase, se rodea de pasividad y pesimismo. Este ser está aceptando de ante mano la derrota. Aparece vencido por la adversidad aun antes de iniciar la batalla. Es una expresión que resume la resignación y la impotencia. El ser humano se siente incapaz ante ciertos acontecimientos de la vida y prefiere mantenerse al margen de la lucha. Pero, en esta derrota, no se siente solo, para su consuelo utiliza la colectividad, ya que de esta manera es más fácil aceptar su penosa situación: "Lo que a mí me sucedió no es nada, figúrese que en la casa de la vecina los ladrones casi se llevan a los dueños" (Naranjo 1989: 39). Claro el sabor de lo amargo, de la pena o de la derrota aparentemente se suaviza, pero la realidad del acontecimiento permanece.

Con el uso de esta frase, solamente tratamos de engañarnos a nosotros mismos. Naranjo considera que esta es una reflexión cotidiana. Se podría decir que es la oración más corriente y sutil de nuestro lenguaje. Ante el primer obstáculo, ante la primera negación, ante la más tibia duda cae con una determinación de tímidas esperanzas. Gracias a esta actitud, el pensamiento y el esfuerzo del costarricense son mínimos. Normalmente, espera que las soluciones vengan 
como regalos. Sueña con la superación personal de pocos esfuerzos. Esto también está relacionado con ese sentimiento que fue creado por un gobierno paternalista que le fomentó en el ser costarricense una dependencia enfermiza. Por lo tanto, este espera que el gobierno resuelva todos sus problemas sin que los ciudadanos tengan que hacer mucho esfuerzo.

El conformismo, dice Luis Barahona, puede verse en tres aspectos de la vida del costarricense: "En lo religioso equivale al fatalismo, en lo social al conservatismo y en lo político a la auto-marginación dentro del proceso democrático" (González 1995: 5). Como se puede observar, la frase qué le vamos a hacer muestra esa actitud de pesimismo y derrota antes de empezar la batalla porque para qué molestarse si es lo que nos ha deparado el destino y nada se puede hacer. Es mejor resignarse ante los embates que nos da la vida:

\footnotetext{
El qué le vamos a hacer integra a esa realidad, hace olvidar un sueño, una pretensión ajena a lo normal. El costarricense se conforma y se consuela, ha vuelto a su estado original, a su no acostumbrada ambición. Por eso el qué le vamos a hacer está muy cerca del así somos... El así somos, y el gesto perdido de voluntad de qué le vamos a hacer le sigue como conclusión reflexiva de que no vale ningún intento: Así somos, que le vamos a hacer. (Naranjo 1989: 39)
}

Después de estas expresiones colectivas, pasamos a analizar las dos expresiones individuales: A mí qué me importa y De por sí. La primera aparenta indiferencia ante los sucesos personales y colectivos. En ella, se encuentra una salida rápida y poco comprometedora: "Busca en la insinceridad de la desvaloración, liberarse de las preocupaciones que tiene menoscabándolo. Pretende insensibilizarse ante el golpe que le ha dolido. Por diversos caminos mentales trata de recuperar su fuerza, pero exteriormente se defiende con una capa de indiferencia" (Naranjo 1989: 50). En un acto de defensa personal, prefiere perder la sensibilidad, no quiere ser parte de la realidad. Se deja rodear de la mentira y toma una actitud irresponsable. Adquiere un divorcio con la sociedad al no querer ser parte de la humanidad: "A mí qué me importa enseña indiferencia, insensibilidad, inconsciencia, deshumanización, irrealidad caprichosa, mentira, irresponsabilidad, consuelo cobarde, carencia absoluta de valor y de independencia por la puerta del escape, nadie llega a independizarse con los ojos y oídos cerrados" (Naranjo 1989: 55-56).

Una vez más, en el caso particular del costarricense, esta frase deja ver el individualismo costarricense: "Este es el fiel retrato del individuo burgués" (Naranjo 1989: 50). La misma Naranjo reconoce que más que individualismo lo que denota es un egoísmo innato de este pueblo. Pasa la vida tratando de ignorar la realidad. Ha crecido con una mentalidad cerrada frente a los diarios aconteceres nacionales e internacionales. Prefiere creer que Costa Rica es un paraíso terrenal y que nada puede cambiar esa realidad. Desafortunadamente, esas actitudes han creado una serie de mitos que son trasmitidos de una generación a otra, provocando insensibilidad, ignorancia o irresponsabilidad.

En cierta forma, De por sí es una frase muy similar a la anterior. Esta permite ver cómo las personas juegan con su medio, desvalorizando lo acontecido. Puede usarse para expresar desprecio ante un suceso o para justificar las acciones y sobre todo para cuando se siente criticado o incomprendido: "El hombre se atreve a actuar porque no tiene nada que perder, porque ha valorado las circunstancias y dentro de ellas da lo mismo actuar...Es el consuelo del hombre pesimista, sumido en su propio fatalismo, seguro de que el porvenir está plagado de ajenos y propios de por sî" (Naranjo 1989: 72).

Dentro de los ámbitos costarricenses, esta expresión tiene tonalidades de evasión. Naranjo considera que en Costa Rica no hay pasiones verdaderas. Es un ser tibio que se 
conforma con poco: “Tiene horror a lo excesivo, se aclimata pronto en el término medio y no quiere que lo incomoden" (Naranjo 1989: 78). No es que el costarricense sea pacífico como lo expresa el mito; más bien, es cómodo. Prefiere no inmiscuirse en grandes empresas. Deja pasar las complicaciones porque de por sí... no se puede resolver nada. Si los políticos son malos y corruptos nada se puede hacer porque al final todos son iguales. Si los artículos de la canasta básica van a subir, nada se puede hacer porque de por sí, siempre van a subir de precio. Esta actitud que tiene que ver con la tolerancia es una característica de la cosmovisión del "Tico" como señala González Dobles: "Este sentimiento dificulta el sentido de responsabilidad en asuntos no percibidos como propios" (Gonzalez 1995: 64).

La última expresión que plantea Naranjo es Idiay. Esta expresión es muy usada por el costarricense especialmente cuando no se quiere asumir una verdadera comunicación, sino que se quiere dejar patente su presencia o quiere hacer valer sus derechos. Naranjo considera que es una manera que tiene el tico para indagar la situación en que se encuentra. En cierta forma, Idiay encierra una dualidad del contenido. Por una parte, incita a continuar con la conversación, y por otra, termina con el relato. El idiay no busca un confrontamiento real. Es solo una forma de ser reconocido ante la sociedad. En muchos casos, es simplemente una muletilla que se usa para salir de apuros cuando no se sabe qué decir. Por otro lado, la expresión también puede ser usada para confrontar a otro en una situación en donde quiere aparentar que está molesto, pero busca más bien un arreglo verbal a la desavenencia. Dice Naranjo que el costarricense tiende a reaccionar rápido frente a la agresión y el Idiay es una manera de mostrar un cierto desafío.

\footnotetext{
El Idiay es un llamado al parlamento, a la explicación. Cree el costarricense en la palabra y es fácil verlo extraviado en su propio discurso. Prefiere explicarse a ser y se ha hecho experto en materia de explicaciones. En cada costarricense vive un abogado defensor de sus derechos, de sus equivocaciones y sus aciertos. El punto de vista de cada quien en nuestro país, se expone con brillantez y en la pasión de las palabras el costarricense se pinta autorretratos graciosos, se descongestiona, se hace lavados corporales y mentales. (Naranjo 1989: 86)
}

Al costarricense en la realidad no le gusta la confrontación y prefiere pasar inadvertido. De ahí, que el idiay tenga intrínseco ese sentimiento de "déjeme vivir en paz”, de llevemos la fiesta en paz.

\footnotetext{
El idiay, como llamada de atención hacia sí mismo, no sale del círculo egoísta y cómodo en que se entrapan los costarricenses en una monotonía que los va durmiendo plácidamente, siempre dentro del concepto de propiedad personal intocable, en donde no se quiere la perturbación del riesgo, menos aún la dificultad de poner en entredicho su valor y su individualidad, esta última figurada en la máscara del irresponsable desapego a lo humano. Y cuando despierta de esta modorra, con la sed del idiay, viene a exigir el tenue calmante de un aprecio con miles de figuras falsas que tienen un fatuo uso en el brillo del nombre. (Naranjo 1989: 90-91)
}

En pocas palabras, Naranjo considera que esta última frase de cierta manera resume el fatalismo y el "rendimiento fácil con una disculpa lista a disculpar una modalidad del: asî somos, que le vamos a hacer" (Naranjo 1989: 92).

\section{Radiografías de la sociedad}

Naranjo, a través de las observaciones etno-sociológicas, nos muestra unas radiografías sobre el comportamiento social de los ticos. Por otro lado, en las viñetas narrativas de Contreras podemos ver esas mismas expresiones de la comedia humana porque aquí los planteamientos se han vuelto la palabra en acción. Quiero empezar con "El lago de los 
cisnes". Relato sumamente irónico y sarcástico que se abre con una bella joven periodista que irónicamente el narrador la llama "la heroína del noticiero más popular" (Contreras 2000: 76). Esta joven ha llegado a la Reforma, la cárcel más importante y más peligrosa de Costa Rica, para hacerle una entrevista a un reo de los que se supone se encuentran en mínima seguridad. Se nos dice que la joven periodista se encuentra en esa zona "sin mediadores, con apenas los guardias indispensables" (Contreras 2000: 76) lo cual viene a reforzar la burla que le hace el narrador a la falsa heroína que lo único que busca es el sensacionalismo para aumentar su popularidad y el rating del noticiero. El preso, a quien ha ido a entrevistar, se nos presenta como un hombre un poco distraído, enfrascado más bien en su mundo, que no ha cometido un crimen violento y no representa ningún peligro para la sociedad.

La entrevista casi resulta un fracaso porque el recluso no podía darle con lujo de detalle las razones por las cuales él se encontraba en el reclusorio. La pregunta con la que se abre esta historia dice: ¿Usted sabe porque estoy yo aquí? Esta es una pregunta que tiene dos interpretaciones: tiene usted el conocimiento de lo que me aconteció o le gustaría saber porqué purgo esta condena. La periodista quien lo interpreta como aquí voy a sacar una buena noticia, se encuentra con el inconveniente de que el preso no está muy seguro del porqué se encuentra encerrado: "solo se acordaba que era diciembre y de que los chiquillos tenían hambre" (Contreras 2000: 76). Como se puede apreciar, la pregunta con la que se inicia el texto es más bien una llamada de auxilio por parte del preso que quiere que alguien le explique porqué razón se encuentra en la Reforma. Quiere saber qué es lo que ha hecho tan espantoso para merecer estar en un lugar tan terrible y alejado de su familia que lo necesita. Pero, la insensibilidad y el individualismo de la joven reportera no permiten leer entre líneas lo que verdaderamente está gritando a voces el presidiario. Para buena suerte, de la intrépida periodista, otro recluso le espeta: "A ese le echaron aquí porque fue el que mató a Chaicowski" (2000: 76). La periodista inmediatamente informa a su público televidente que este es el desalmado que mató al cisne del parque Chino en San José.

Mientras el hombre trata de explicarle los verdaderos motivos que lo llevaron a cometer ese crimen, ella no es capaz de prestarle atención porque está más interesada en una noticia sensacionalista. Aquí se puede ver claramente la expresión A mí qué me importa lo que haya pasado con su vida y con la de su familia. Claro que no le importan las verdaderas razones por las que ese hombre está preso. Por eso, sin darle crédito se aleja de él, tal vez en busca de una mejor noticia que le dé más popularidad y rating. El hambre, la pobreza, la desesperación que lo llevaron a matar al cisne para darle de comer a sus hijos, no tiene la mayor importancia. Contreras en esta viñeta deja sentado que a nadie realmente le importa el sufrimiento de este hombre. Los medios de comunicación están buscando una noticia impactante, no están tratando de ayudar a nadie. Por otro lado, la actitud del preso deja ver una gran indiferencia hacia lo sucedido. Al principio no puede casi ni recordar porque está ahí. Muestra una gran apatía ante la vida y es casi con Qué le vamos a hacer, así es la vida. Él no es el único que está en la cárcel y además qué se puede hacer, nada. Ni siquiera le dejaron que se comiera "el pato pescuezudo" (Contreras 2000: 77) con su familia como alegaba en tono de reproche cuando vio alejarse a la periodista y a su equipo de camarógrafos. Vivimos en un mundo en donde cada cual está por lo suyo y realmente los problemas personales no le importan a nadie, a menos que estos puedan beneficiar al otro individuo.

En la viñeta "Noticia incompleta", nos encontramos de nuevo a la prensa cubriendo un evento insólito: "Mujer madura, casada, madre de cuatro hijos, encontrada aplaudiendo 
en una esquina", rezaba el encabezado de un diario vespertino (Contreras 2000: 17). Este incidente es cubierto por la prensa sensacionalista que trata de encontrar las razones para tan inusitado suceso. Lo interesante es que esta noticia queda a medio cubrir porque cuando la susodicha reacciona de su shock, no quiere dar por menores de lo que le aconteció. Un hermetismo profundo la envuelve. Sin embargo, por medio del narrador nos enteramos que un chico, como de la edad de uno de sus hijos, se le acerca con un cuchillo y le comenta: "doña ... tengo dos días de no hacerle a la piedra" (Contreras 2000: 18). Y ella como es de esperarse le entrega la cartera, la cual el joven rechaza enérgicamente reventándola contra el suelo mientras le decía: “doña, ... usté no entiende, llevo dos días de no fumar piedra, doña apláudame, apláudame, doña” (Contreras 2000: 18).

En este texto, nos encontramos probablemente dos individuos de diferente clase social. El chico un marginado, delincuente que está tratando de regenerarse y ella una señora respetable madre y esposa. Ahi vamos es la frase que define la actitud de este joven que va por la vida tratando de encontrar un puerto donde anclar. Por eso, busca el apoyo de esta mujer. Normalmente, no queremos enfrentarnos solos a los problemas, pero, como dice Naranjo, es solo un disfraz, una fachada. Al final caminamos solos como el chico que se "marchó, pálido como un espanto tambaleante aun. Un poco más tranquilo... tal vez" (Contreras 2000: 18). Nótese que el narrador no puede asegurar que después de este incidente el joven realmente pueda reivindicarse ante la sociedad. Este fue solo un acto desesperado en donde esperaba encontrar comprensión, solidaridad y apoyo. La mujer, por otra parte, aplaude como le pide el joven, pero realmente no entiende lo que este le está solicitando. No es el acto literal ejecutado por ella lo que él esperaba. La reacción de la mujer es más un acto de supervivencia que de solidaridad. Ella lo único que ha visto es el cuchillo del chico en la mano. Lo más probable es que piense que el joven la va a asaltar. No puede enfrentarlo con "un idiay a vos que te pasa conmigo" porque tiene miedo de la reacción del chico y por eso opta por la conciliación. Es mejor aparentar que ahí no está pasando nada y seguirle el juego a este pobre diablo.

Una vez pasado el incidente, la reacción de la mujer es una clara muestra del De por sí. Ella sabe que tal vez nada vaya a cambiar en la vida del joven. Lo más probable es que vuelva a caer en las redes de la drogadicción. Cuando sale de su shock, decide permanecer callada y no compartir con nadie la experiencia vivida, porque ella sabe que si le explica a su esposo lo acontecido probablemente la critique por tonta, por ingenua. Ella sabe que si le explica a la prensa que ella aplaudía por pedido de un desgraciado, lo convertirían en un carnaval. De por sí, si decía la verdad lo único que iba lograr era la burla y el choteo de los demás. Lo triste aquí es que al igual que la viñeta anterior, el individualismo tiene un peso más fuerte que la verdadera solidaridad entre sí, porque no queremos que nos choteen.

El siguiente cuadro "iSaludos, noble bandera!” nos brinda un discurso muy irónico, cargado de una gran crítica social al desinterés que puede mostrar las autoridades públicas por los problemas que atañen a un grupo minoritario y casi inexistente en el país para el grueso de la población: los indígenas. Un aspecto de la idiosincrasia del "tico" es la convicción de que en Costa Rica el $85 \%$ de la población es criolla. En otras palabras, casi todos somos descendientes de europeos. En esta viñeta, Contreras nos muestra la situación de un indígena, el cual ha agotado todos los medios gubernamentales para exponer su queja: "Antes de tomar tan tremenda medida, ya había subido y bajado cada escalón, recorrido cada pasillo, doblado cada esquina y había hecho cola frente a cada ventanilla de cuantos vericuetos tiene la justicia" (Contreras 2000: 101). Este 
hombre ante la indiferencia del sistema que muestra ese "a mí que me importa" se ve obligado a tomar unas medidas más drásticas para así tal vez ser escuchado: "Lo de subirse al árbol fue una idea que le vino cuando se convenció de que nadie iba a detenerse a escuchar a un indio quejarse de que los peces amanecían flotando bocarriba en los ríos, de que los árboles no morían de pie, de que les estaban güequeando la montaña con eso de la explotación petrolera" (Contreras 2000: 102). Nótese que este hombre agotó todos los recursos legales y cuando no encontró a nadie que atendiera sus peticiones o se interesara por su problema, tomó la drástica resolución de subir al árbol más alto del parque central envuelto en la bandera nacional, máximo emblema patrio, como un llamado de atención: "Yo también soy costarricense".

Podemos apreciar la ironía y la irreverencia con que Contreras maneja esta historia, propio del discurso postmoderno que juega con conceptos excelsos para desvirtuarlos a razón de demostrar el deterioro moral de una sociedad que se desmorona. Ya desde el título de la obra podemos ver cómo se juega con un concepto sagrado que se expresa en el Himno a la bandera, escrito por Porfirio Brenes: "Salud noble bandera de blanco, azul y rojo/ Jamás ningún sonrojo/ fue mancha a tu esplendor" (Zúñiga 1974: 206). En esta viñeta, se le deja saludos a la bandera. En otras palabras, no existe ninguna patria para este individuo indígena. La patria lo ha abandonado, le ha dejado saludos. Casi podríamos decir que se juega con un concepto de patria inexistente que le ha borrado como a uno de sus hijos. A nadie en el gobierno le importa la suerte que estas personas pueden correr. Es más importante el dinero que pueden recibir de las compañías extranjeras que explotan el suelo en busca de petróleo u otros minerales.

La destrucción del ecosistema y de las tierras de estos pobres indígenas no le interesa a nadie. Lo único que logra el hombre es que lleguen las autoridades públicas, entre ellos: la policía, los bomberos y las cruz roja a obligarlo a bajar del árbol: "Y lo bajaron aun agarrado de la bandera" (Contreras 2000: 102) ante la presencia de unos borrachos que al encontrarse con tal acto: "cantaron el Himno Nacional con una mano en el pecho, como se enseña en las escuelas" (2000: 102). La irreverencia con que se trata este incidente es mordaz. Los que reconocen el emblema nacional que dignifica son un grupo de borrachos, vistos por el resto de la sociedad con desprecio, pero es este grupo menospreciado quien reconoce el verdadero significado de la bandera en este episodio. Sin embargo, que le vamos a hacer con la situación de unos cuantos que se quejan porque ha llegado la "civilización" a sus tierras. No se puede parar el desarrollo aunque esto signifique la destrucción de un grupo étnico. Los gobernantes están más interesados en el progreso económico de unos cuantos. A fin de cuentas, los grupos indígenas están marginados y casi borrados del imaginario nacional.

Esto nos lleva a la última viñeta que examinaremos para este trabajo denominada "Un indio". En este relato, nos encontramos a dos burócratas conversando sobre un ritual que realizaba puntualmente cada año un indígena que bajaba de Talamanca, para rendir tributo a sus muertos en el Museo Nacional por los últimos 15 años, sin faltar uno solo: “¿Y por qué se lo permiten?, preguntó el director entrante al director saliente, ¿No se supone que esto es el Museo Nacional?” (2000: 105). Se puede apreciar el sarcasmo en la última pregunta: “¿No se supone que esto es el Museo Nacional?" Aunque los matices que envuelven esta historia son diferentes a la anteriormente valorada, lleva una crítica muy similar. La población indígena en Costa Rica es un mito. En los libros escolares, casi se presentan como si fueran más bien parte del pasado histórico de Costa Rica que de la realidad nacional actual. A los indígenas se les admira detrás de las vitrinas de los Museos, pero no se tiene en cuenta la realidad social que 
muchos de ellos viven. Es probable que se tenga una idea de que algunos habitan en Talamanca y Guatuso pero no se sabe a ciencia cierta cómo viven, cuáles pueden ser sus necesidades, cuáles son sus ritos o sus costumbres. Por lo tanto, no se puede respetar lo que ignora.

El director saliente comenta "que se trataba de un Chamán y que no eran enredos eso que cantaba, sino cánticos ceremoniales heredados de sus mayores, esos que ahora yacían insepultos a la vista de todo el mundo" (Contreras 2000: 105). La actitud del director saliente hacia el Chamán muestra una cierta comprensión a la necesidad que tiene este hombre por honrar a sus difuntos y por eso nunca le ha negado la entrada al museo porque qué le vamos a hacer. Si este hombre tiene que venir al museo porque le robamos sus muertos para que el pueblo pueda aprender de nuestra herencia precolombina, lo menos que podemos hacer es dejarlo entrar gratis una vez al año para que cumpla con su ritual. Pero el director entrante muestra una actitud totalmente indiferente a las necesidades de este hombre. Aquí se nos presenta un choque entre el presente y el pasado que hasta ese momento sólo había estado cubierto por libros de la historia.

La actitud del director entrante es la de a mí que me importa que este hombre tenga que honrar a sus muertos en frente del público. No se produce un aprecio por la cosmovisión del indígena que tiene que sobrevivir en el mundo moderno que no le comprende. Más bien ve la oportunidad de sacarle provecho a la situación: "El director entrante se encogió de hombros, miró la fecha en su reloj, la anotó, mandó a sacar algunas fotografías y, una vez asumido al cargo, añadió la ceremonia al programa de la institución" (Contreras 2000: 106). Este hombre es un oportunista que no muestra ningún respeto por las tradiciones de los pueblos indígenas. Lo irónico es que el director debería de ser un estudioso de los grupos indígenas y mostrar un deseo por aprender más de las tradiciones de esos pueblos pero solo puede captar la oportunidad de sacarle provecho a la situación porque al negar la verdadera realidad indígena es como se puede legitimizar el mundo actual. Entonces, el indígena representa la otredad, esa otra realidad que no queremos aceptar porque nos desbalanza el mundo que hemos creado.

Tanto Carmen Naranjo, desde su estudio sociológico, como Fernando Contreras, en su trabajo literario, muestran por menores sobre la concepción que tiene el tico sobre sí mismo y su mundo. La postura de estos escritores nos ayuda a comprender mejor el ser y actuar del costarricense en sociedad. Las expresiones analizadas por Naranjo en su ensayo nos permiten ahondar en su significado y comprender mejor lo que se encuentra detrás de cada una de ellas. Mientras que las viñetas de Contreras son como pequeños cortes cinematográficos que nos dejan ver de una manera más precisa esas actitudes en acción. No cabe duda que ambos escritores son grandes conocedores de la idiosincrasia nacional.

\section{Bibliografía}

Carrillo Torea, Guadalupe. 2008. "Irrupción de la temática Urbana el al Literatura Argentina y Latinoamericana”. Revista de Estudios Latinoamericanos. 47: 65-77.

González Dobles, Jaime. 1995. La patria del tico. San José: Editorial Antares.

Martínez Santiago, Luz. 1987. Carmen Naranjo y la Narrativa Femenina en Costa Rica. San José: Editorial Centroamericana Universitaria. 
Naranjo Coto, Carmen. 1989. 5 temas en busca de un pensador. San José: Editorial Costa Rica.

Soto Quesada, Alvaro. 1986. La Formación de la Narrativa Nacional Costarricense (1890 1910) Enfoque Histórico Social. San José: Editorial de la Universidad de Costa Rica.

Zúñiga, Daniel. 1974. Lo que se canta en Costa Rica. San José: Imprenta Universal. 
